\title{
Professional Selection of Personnel as a Factor of Sustainable Development of the Mining Region
}

\author{
Natalia Zaruba ${ }^{1}$, Olga Nikiforova $^{1}$, and Konstantin Vostrikov $^{1}$ \\ ${ }^{1}$ T. F.Gorbachev Kuzbass State Technical University, Kemerovo 650000, Russian Federation
}

\begin{abstract}
The subject of the study is the organization of professional selection of personnel as a factor of sustainable development of the mining region. Dynamic changes in the market economy have created a number of problems in the ideology and practice of personnel selection in the coal industry, caused by the low level of academic mobility of specialists. The purpose of this work is to analyze the problems of professional selection of personnel in the coal industry in order to determine the level of academic mobility and develop proposals for their solution. Used research methods: analysis, specification, description, generalization modeling. The study revealed some problems of professional selection of personnel for the coal industry considered a deterrent to the sustainable development of the coal industry. These problems include the following drawbacks: the low level of expertise of experts in General, in matters of professional diagnostics, and that is important in today's dynamic conditions, diagnostics of academic mobility of a specialist in the coal industry. The scheme of professional selection of personnel present, which can be applied in order to solve some of the listed problems. In conclusion, the article substantiates the fact that it is necessary to review and correct the existing methodological tools, methodology for selecting and evaluating the professional suitability of personnel for the coal industry.
\end{abstract}

\section{Introduction}

Sustainable development of the mining region in the modern market economy characterized by the reform of organizations and enterprises, changes in the structure and number of personnel, the emergence of new professions, specialties. The creation of new and unique jobs, automation and robotics of production, which requires a review, adjustment and improvement of approaches to professional selection of personnel in the coal industry. Unfortunately, the postulate that professional selection aimed at identifying a reliable level of compliance of a person's abilities and capabilities with a certain professional activity implemented in practice, and most enterprises and organizations, including those in the coal industry, face the problem of personnel selection. This evidenced by the results of many studies, for example, N. p. Kalinin and V. G. Makushina claim that labor productivity increases by up to $30 \%$ with scientifically based professional selection, staff turnover decreases by $10-60 \%$, and staff satisfaction with the process and results of work increases [1]. K. I. Ivanov-Muromsky revealed that only $8-10 \%$ of operators 
have compliance of psychological and physiological indicators with the requirements of the profession [2]. D. Cooper and A. Robertson found that the economic effect of professional selection is $6-20 \%$ of the existing level of production efficiency [3]. According to the UN, professional unfitness is the cause of $40 \%$ of road accidents, approximately $65 \%$ of industrial injuries and accidents in the mining industry, and $80-90 \%$ of power plant violations [4]. According to experts From the U.S. Department of labor's office of employment and training, the income generated by the difference in productivity between employees who was select using psychological aptitude tests and randomly selected individuals is approximately equal to the annual income of corporations [5].

Currently existing private recruitment offices and recruitment agencies, human resources departments, etc. often carry out the selection of personnel on formal grounds, limited to interviews and analysis of the track record, and not a comprehensive assessment of the employee's professional suitability for the chosen type of professional activity. In addition, the leading mining industry in the region, such as coal, with its inherent level of increased production risk, requires a fundamentally different approach to recruitment.

The reveal contradiction between the relevance of the search for a new approach to the formation of human resources to create conditions for the sustainable development of the mining region and insufficient attention to the implementation of a set of measures for professional selection adapt to the specifics of the coal industry, serves as the basis for the need to revive and update the theory and practice of scientifically-based targeted professional selection.

The purpose of our research work is to study the reasons that hinder the effective implementation of the adapted professional selection of personnel for the sustainable development of the region, as well as to develop proposals for their elimination in the conditions of the mining region.

The methodological basis of this work was the research of domestic and foreign scientists on the organization of professional selection and efficiency of personnel management for the purpose of sustainable development of the mining region

The main method for undertaking research is the analysis of materials from scientific and periodical publications, statistical and reporting documents on the research topic. The article uses methods of concretization, comparison and generalization that allow, logical analysis, to develop proposals for solving the identified problems. The proposed model of professional selection of personnel, aimed at creating conditions for sustainable development of the mining region, is formed generalization of research materials using a graphical method.

\section{Results and discussion}

Modern features of the labor market in Russia characterized by monopolization, the dominance of the private sector of the economy, the liquidation of enterprises and the reduction of production, forced labor migration, and an increase in shadow employment. All this creates, as modern practice shows, inefficient distribution of labor resources, leakage of qualified personnel, unemployment, social insecurity of the population, and under-production of national income. Existing organizations and enterprises in the mining region face great difficulties in finding the optimal number of employees and improving the efficiency of their use [6]. The causes of this problem are in the competence of the authorities and business who need to ensure complete control of observance of the labour legislation with the aim of social protection of released personnel (including their professional training and/or professional development), predictability and the prospects of development of the labour market. 
An important element of the system of professional selection for the sustainable development of the region is the availability of appropriate tools. The absence in our country of production of special equipment for psychophysiological, neurodynamic, sensory, cardio-respiratory and other measurements, special transport for moving this equipment, target research centers, etc. [7] aggravates the problem under consideration. Of course, the creation of these tools requires not only large-scale research and development, but also considerable material costs.

Optimization of the process of professional selection of the mining region related to the educational sector. The current education system trains specialists from the past and provides graduates with inefficient intellectual tools $[8,9$, etc.]. The modern system of professional education should significantly restructure educational programs in order to update the focus on the technologies of the future. In addition, professional selection in Russian carry out by employees without special education, although this process involves knowledge of educational, psychological, physiological, clinical, and professional diagnostics procedures, and knowledge of the labor market in their industry and region. This competence confirme by proper qualifications. In the modern world, in developed countries, professional selection is in most cases the task of HR Directors and specialists with appropriate education. In our country, the requirements for competencies in accordance with the Federal higher education system for the specialty "Psychology of performance", firstly, do not correspond to the competence of an expert in the field of professional diagnostics and consultation; secondly, there is no professional standard in this area. The demand for and economic feasibility of spending on their training suggests that the Ministry of science and higher education is interested in training such specialists, as well as the business of the mining regions.

For the purpose of sustainable development of the mining region, in our opinion, in accordance with the scientific provisions on professional selection, the initial procedure for professional selection should be a professionographic study of various types of professional activity, reflecting the compliance of the employee's function, the requirements for his personal and psychophysiological characteristics. The professionogram allows you to choose the most effective strategy and tactics of selection, develop criteria and methods of professional selection of specialists. The existing practice of selection using a modern database of professional charts requires a new scientific content and systematization, it does not take into account the specialization and features of the performance of specific labor functions of the mining industry. The professionogram should include contraindications to a specific profession and position, including health indicators and personal qualities of the applicant: stress resistance, communication skills, etc.

Based on the level of their significance, it is important rationally differentiate the professionally important qualities presented in the professionogram into absolute (genetically determined and poorly trained individual characteristics of a person; for example, neurodynamic characteristics); relative (amenable to development and training) and anti-criteria (contraindications and qualities that contradict the considered type of professional activity). Accordingly, according to the degree of professional suitability of personnel, three groups of applicants are distinguished: suitable, conditionally suitable and unfit.

The inertia of the research mentality noted as a hindering factor when updating approaches to professional selection for the purpose of sustainable development of the mining region. The analysis of theoretical and practical approaches to personnel selection revealed the use of only traditional methods of personnel selection in the process, which include: analysis of candidates ' resumes, questionnaires, telephone interviews, psychological testing, and interviews. No less relevant in the current labor market conditions when selecting personnel are methods that assume the lability of diagnostic 
procedures, which reduces the likelihood of pre-training of the candidate; and identifying the level of compliance of personnel in key competencies: professional tests, cases, projective questions, stress interview, brainteaser interview, etc.

The highest intellectual and material costs associate with the creation or acquisition of appropriate equipment by the psychophysiological block of professional selection. Allows identifying a wide range of professionally significant indicators for candidates levels of performance and fatigue, stress resistance, speed of sensorimotor response, sensitivity threshold, coordination and accuracy of movements, quality of functioning of sensory systems, properties of the nervous system, type of higher nervous activity as shown by E. M. Kazin, etc. [9], the introduction of automated computer systems (complexes) reduces the complexity of psychological and psychophysiological diagnostics, processing results that do not exclude an individual interview with a candidate, allowing you to adjust the indicators of diagnostic procedures.

Note that the success of the professional selection also determined by the extent taken into account the possibility of formation of individual style of professional activity, to compensate for underdeveloped professionally significant features due to the strong. In joint activities (the sphere of "man-man"), the possibility of influencing the effect of mutual complementarity of people's properties should be taken into account. We add that in modern conditions, digitalization, industrial automation, Informatization and intensification, which generate complex types of work and dynamic technologies, change the structure of a person's professional competence. The variety of possible options for organizing working groups (for example, project groups) is expanding, the uniqueness of work at each individual workplace is increasing, so not only styles of activity, but also strategies of behavior, structures of "integral individuality" (according to V. S. Merlin and others) have become important [10].

In the conditions of sustainable development of the mining region, the tasks of psychophysiological selection in professions of the "man-technique" type solved by engineering and psychological design of technical means and the activity itself.[9] The ergonomic approach in the aspect of adaptation of technical means to psychophysiological features of the person allows reduce the rigidity of the requirements for the professional suitability of the employee. The exception is the first type of profession, and professions with extreme working conditions.

The lack of a Bank of empirical psychodiagnostic data for various professional groups, the non-proliferation of mathematical modeling and standardized methods that have statistical norms and meet the requirements of validity and reliability, exacerbate the existing problem of professional selection for the sustainable development of the mining region.

The solution of the described problems is quite time-consuming and requires the activation of the scientific community and human resources agencies, and systematic investment. However, their solution will reduce the cost of finding, hiring and firing unsuitable employees, reduce occupational injuries and occupational morbidity, promote the rational use of labor resources, and ensure the optimal functioning and success of enterprises (organizations) in the mining region.

Formation of a model of professional selection of personnel for the purpose of sustainable development of the mining region (ill . 1) based on the analysis of empirical and theoretical data on the organization of the professional selection and management staff, and includes a combination of variables, which, from our point of view, predictors of success in the selection process. The effectiveness and technological efficiency of the search and selection of personnel provided by preliminary marketing work, analysis of the features of professional activity, correctly selected criteria and methods. 
The valeological and economic importance of the issue under study suggests the feasibility of creating a professional diagnostic laboratory that takes into account the range of mining production and performs, in addition to professional selection, the examination of working capacity; identification of persons in need of rehabilitation, evaluation of its effectiveness; ergonomic study of workplaces, etc.

\section{Conclusion}

Thus, the efficiency of professional personnel selection with the goal of sustainable development in the mining region takes into consideration the many paired conditions. Conditions of the external social environment and internal environment of the organization, existing norms of behaviour and interaction of people in specific working groups, individual characteristics of the subject, the specifics of the organization, specific conditions of professional activity, etc.

Under the influence of multidirectional and multi-level factors of the mining region, the complexity of the problem of professional selection of personnel for the purpose of its sustainable development forme. Optimization of professional personnel selection with the goal of sustainable development of mining region, in our opinion, determined by the control over the observance of legality in the sphere of labour relations, labour market development; the need of training in the field of professional diagnostics and Advisory services; activation of the scientific sector for the development and production of special equipment, software support of the process; creation of modern adapted and scientifically based databases of professional charts and criteria for professional selection in various professional groups, and first of all, in groups of high-risk professions. industries and enterprises of mining regions.

The implementation of science-based professional selection when eliminating the problems described above will contribute not only to improving production efficiency, preventing occupational diseases, reducing occupational injuries, extending labor longevity, increasing job satisfaction, and rational use of labor resources, but also to the sustainable development of mining regions.

\section{References}

1. N. P. Kalinina, V. G. Makushin, Influence of working conditions on its productivity (Economics, Moscow, 1970)

2. K. A. Ivanov-Murom, Psychophysiology of the operator in the system "man-machine" (Naukova Dumka, Kiev, 1980)

3. D. Cooper, A. Robertson, Psychology in personnel selection (Peter, Saint Petersburg, 2003)

4. A. G. Eisenberg, G. M. Isenberg, Proceedings of ISEA, 90:4, 76 (2013)

5. K. M. Gerchikov, Personnel Management: employee - the most effective resource of the company: teaching manual (INFRA-M, Moscow, 2010)

6. O. Nikiforova, T. Yakushina, R. Mamedov, E3S Web of Conf., 105, 04013 (2019)

7. E. M. Kazin, A. I. Fedorov, T. S. Panina, N. A. Zaruba, World of education, 1, 146 (2001)

8. E. M. Kazin, O. A. Nikiforova, A. I. Fedorov, Human Physiology, 17:3, 145 (1991) 
9. V. A. Tolochek, Izv. Saratov. Univ. (N. S.), Ser. Educational. Acmeology Developmental Psychology, 7:2, 118 (2018) DOI: 10.18500/2304-9790-2018-7-2-118128

10. K. M. Gurevich, Professional fitness and basic properties of the nervous system (Nauka, Moscow, 1970)

11. N. A. Zaruba, N. N. Egorova, Coal in the 21st Century: Mining, Processing and Safety, 39 (2016)

12. N. Egorova, N. Zaruba, K. Dusan, E3S Web of Conf., 105, 02011 (2019)

13. N. Zaruba, N. Egorova, P. Kosinskij, E3S Web of Conf., 15, 04003 (2017) 